\title{
Estrés oxidativo y el uso de antioxidantes en la producción in vitro de embriones mamíferos. Revisión
}

\author{
Viviana Torres-Osorio ${ }^{\mathrm{a}^{*}}$ \\ Rodrigo Urrego ${ }^{b}$ \\ José Julián Echeverri-Zuluaga ${ }^{\text {a }}$ \\ Albeiro López-Herrera ${ }^{a}$
}

a Universidad Nacional de Colombia, Grupo de Investigación BIOGEM. Medellín, Colombia.

${ }^{\mathrm{b}}$ Universidad CES, Facultad de Medicina Veterinaria y Zootecnia, Grupo INCA-CES. Medellín, Colombia.

Autor de correspondencia: vtorres@unal.edu.co

\section{Resumen:}

La producción de embriones in vitro es una de las biotecnologías de la reproducción animal que ha presentado mayor desarrollo en las últimas dos décadas; sin embargo, los resultados exitosos en estos procedimientos dependen de múltiples factores, entre ellos la presencia de especies reactivas de oxígeno, debido a que el proceso de fertilización in vitro y la manipulación de los gametos y embriones expone a las células a factores endógenos y exógenos que pueden afectar los mecanismos de defensa antioxidante y por consiguiente la calidad de los gametos y embriones. En esta revisión se discutirán algunas fuentes de especies reactivas de oxígeno, el uso de antioxidantes enzimáticos, no enzimáticos y polifenólicos para disminuir el estrés oxidativo en los procesos de producción in vitro de embriones, y su efecto sobre la calidad de los oocitos y embriones, la expresión génica y su competencia para el desarrollo embrionario.

Palabras clave: Antioxidantes, Especies reactivas de oxígeno, Estrés oxidativo, Cultivo in vitro, Desarrollo embrionario. 
Recibido: 03/10/2017

Aceptado: 29/05/2018

\section{Introducción}

La producción in vitro de embriones (PIVE) involucra tres pasos: la maduración in vitro (MIV) de oocitos obtenidos a partir de folículos antrales, la coincubación de gametos masculinos y femeninos o fertilización in vitro (FIV), y finalmente el cultivo in vitro (CIV) de los presuntos cigotos hasta los estadios de blastocistos. Sin embargo, bajo condiciones fisiológicas los oocitos de mamíferos crecen y son fertilizados en el mejor ambiente protector, el ovario y el tracto reproductivo femenino, mientras que en condiciones in vitro los gametos y embriones deben ser manipulados durante la maduración, la fertilización y el desarrollo embrionario en ambientes que generan estrés oxidativo, entre los cuales destacan: la concentración de oxígeno alta $(20 \%)$, en relación al ambiente in vivo $(3 \mathrm{~A} 5 \%)^{(1)}$, la exposición a la luz ${ }^{(2)}$, la composición del medio de cultivo $^{(3)}$, cambios de $\mathrm{pH}^{(4)}$, procesos de centrifugación ${ }^{(5)}$, entre otros ${ }^{(6)}$, lo cual tiene un efecto deletéreo sobre los gametos y embriones, alterando la funcionalidad de biomoléculas como lípidos, ácidos nucleicos y proteínas, y subsecuentemente afectando el desarrollo embrionario ${ }^{(7)}$.

A pesar de que las células cuentan con un sistema de defensa antioxidante enzimático y no enzimático, algunas moléculas antioxidantes han sido utilizadas como suplemento en los medios de cultivo para disminuir la producción de especies reactivas de oxígeno (ERO) en gametos y embriones, con el fin de mejorar su calidad y su potencial

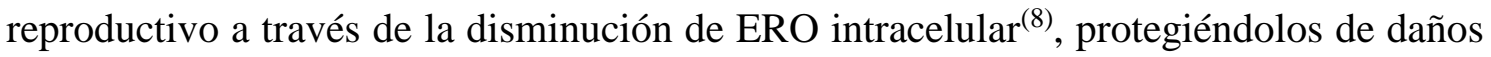
al ADN y otras biomoléculas, y por consiguiente mejorando la competencia de desarrollo embrionario $^{(9-11)}$. El objetivo de esta revisión es analizar el efecto del estrés oxidativo y el uso de antioxidantes en la producción in vitro de embriones, sobre la calidad de los gametos y embriones a nivel metabólico, de expresión génica y marcas epigenéticas.

\section{Especies reactivas de oxígeno y estrés oxidativo}

Las ERO son un grupo de moléculas generadas a través de la reducción parcial del oxígeno molecular; la mayoría de estas especies (excepto el peróxido de hidrógeno), poseen uno o más electrones desapareados, configuración a la que se le denomina radical libre. En condiciones basales, el metabolismo aeróbico está vinculado con la producción de ERO tales como el peróxido de hidrógeno $\left(\mathrm{H}_{2} \mathrm{O}_{2}\right)$, el anión superóxido $\left(\mathrm{O}_{2-}\right)$ y el radical hidroxilo $(\mathrm{OH}-)$, mientras que las especies reactivas de nitrógeno como el óxido 
nítrico $(\mathrm{NO} \bullet$ ), son formadas por la conversión de L-arginina a L-citrulina por efecto de la enzima óxido nítrico sintasa (NOS). Cuando se presenta una producción exagerada de ERO que excede la defensa celular, da lugar a un proceso denominado estrés oxidativo ${ }^{(12)}$, que genera un daño oxidativo a biomoléculas tales como lípidos, proteínas, carbohidratos y ácidos nucleicos, lo que inducen cambios estructurales y funcionales tales como hidroperóxidos de lípidos ${ }^{(13)}$, proteínas carboniladas ${ }^{(14)}$ y DNA con bases oxidadas ${ }^{(7,8)}$ dihidro-8-oxoguanina) ${ }^{(15)}$.

Por otro lado, la cadena respiratoria mitocondrial es susceptible a daño oxidativo; principalmente los complejos I y II por la producción de radicales superóxido y nitrilo, los cuales pueden afectar proteínas mitocondriales y alterar la función de muchas enzimas metabólicas en la cadena transportadora de electrones mitocondrial ${ }^{(16)}$. Además, se ha demostrado que el ADN mitocondrial (mtDNA) es más sensible que el ADN nuclear a estrés oxidativo ${ }^{(17)}$, posiblemente porque el mtDNA carece de histonas, las cuales lo protegen contra el daño de los radicales libres, no cuenta con un sistema de reparación adecuado y está localizado cerca de la membrana mitocondrial interna, el cual es el mayor sitio de producción de $\mathrm{ERO}^{(18,19)}$. Adicionalmente, el daño oxidativo en el mtADN puede inducir mutaciones y alterar la función e integridad mitocondrial ${ }^{(20)}$, lo cual en humanos, da lugar a enfermedades mitocondriales degenerativas tales como Alzheimer, Parkinson y esclerosis amiotrófica lateral ${ }^{(21,22)}$.

\section{Producción de ERO durante la producción in vitro de embriones}

En el tracto reproductivo algunos procesos celulares son regulados por ERO, los cuales actúan como segundos mensajeros generando una respuesta celular específica. Algunas macromoléculas sensibles a modificaciones redox (fosfatasas, quinasas, factores de transcripción) juegan un papel importante durante el desarrollo celular, como la proliferación, diferenciación y muerte celular. En relación a esta última, diferentes niveles de ERO generan diferentes tipos de muerte celular, por ejemplo, bajas concentraciones promueven la apoptosis, concentraciones intermedias generan autofagocitosis y altas concentraciones promueven la necrosis celular ${ }^{(12,23)}$. Durante la MIV, son necesarios niveles fisiológicos de ERO para el reinicio de meiosis de los oocitos arrestados en diploteno, para estimular la liberación de $\mathrm{Ca}^{2+}$ intracelular en el oocito y para estimular la proteína quinasa activada por mitógeno (MAPK) ${ }^{(24,25)}$.

Con respecto a los espermatozoides, niveles fisiológicos de ERO son requeridos para la capacitación, hiperactivación y reacción acrosómica de espermatozoides mamíferos ${ }^{(26)}$. Durante la capacitación espermática, las ERO como el anión peroxinitrato, $\mathrm{H}_{2} \mathrm{O}_{2}$ y NO• tienen un efecto dosis-dependiente sobre la función espermática. A bajas concentraciones las ERO son requeridas para promover el flujo de colesterol, la producción de AMPc, la hiperactivación y la fusión oocito-espermatozoide ${ }^{(27,28)}$. En contraste, un exceso de ERO puede afectar la funcionalidad espermática, debido a que la membrana celular de los 
espermatozoides es rica en ácidos grasos polinsaturados; lo cual la hace susceptible a peroxidación lipídica; además puede afectar la función mitocondrial, la interacción espermatozoide-zona pelúcida, reducir la motilidad espermática y generar un efecto deletéreo sobre el ADN de los espermatozoides, lo cual podría comprometer la fertilidad en los machos ${ }^{(29-31)}$. Por lo tanto, el uso de moléculas antioxidantes es de vital importancia para proteger las células de los altos niveles de ERO y sus efectos deletéreos.

A pesar de los grandes avances en las técnicas de reproducción asistida para simular las condiciones in vivo, dos factores principales contribuyen a la generación y acumulación de ERO in vitro: la ausencia de mecanismos de defensa endógenos y la exposición de los gametos y embriones a ambientes que generan ERO. Por lo tanto, las ERO pueden provenir de dos fuentes: endógenas, en las cuales los oocitos, espermatozoides y embriones inducen su acumulación a través de varias rutas metabólicas y enzimas, incluyendo principalmente la fosforilación oxidativa, NADPH oxidasa y la xantina oxidasa $^{(32)}$.

Entre las fuentes exógenas de ERO se encuentran factores ambientales, como la criopreservación, la concentración de oxígeno, la fuente de energía, el medio de cultivo, y la luz ${ }^{(6,33)}$. El oxígeno es un componente importante de los ambientes oviductal y uterino, y puede tener un papel importante en la regulación del desarrollo embrionario, particularmente a través de la regulación del metabolismo. Ha sido reportado que la tensión de oxigeno encontrada en el oviducto y útero se encuentra en un rango de 5 a $8.7 \%$ en varias especies ${ }^{(34)}$. Diferentes reportes soportan buenos resultados utilizando 5 y $20 \%$ durante maduración y cultivo de oocitos ${ }^{(35,36)}$. Sin embargo, la tendencia es utilizar un $20 \%$ de $\mathrm{O}_{2}$ durante la maduración del oocito, debido a que la ruta de producción de energía a concentraciones de $\mathrm{O}_{2}$ baja ( $5 \%$ ), disminuye la proporción de oocitos en MII, lo cual afecta la competencia de desarrollo del oocito ${ }^{(1)}$. En contraste, un $5 \%$ de $\mathrm{O}_{2}$ durante el cultivo favorece su competencia para el desarrollo embrionario, celularidad y expresión génica relacionada con estrés oxidativo ${ }^{(37)}$. No obstante, se ha reportado que la exposición a altas concentraciones de oxigeno ( $20 \%$ en aire), potencia el aumento de los niveles de ERO, disminuyendo los porcentajes de desarrollo embrionario en murinos ${ }^{(38)}$, porcinos $^{(39,40)}$, caprinos $^{(41)}$, bovinos $^{(42)}$ y humanos $^{(43)}$, generando arresto en el desarrollo, daño en el ADN, apoptosis y peroxidación lipídica, afectando la competencia embrionaria $^{(44)}$. Además, al evaluar la abundancia relativa de RNAm en oocitos, se observa un patrón de mejor calidad cuando los oocitos son madurados en bajas concentraciones de oxígeno $(5 \%)^{(45,46)}$. Estos resultados reflejan los efectos perjudiciales de la concentración de oxigeno atmosférico sobre el cultivo de embriones mamíferos.

Por otra parte, los medios de cultivo, dependiendo de su composición y suplementos, pueden contribuir con la producción de ERO al sistema de producción in vitro de embriones ${ }^{(3,47)}$. El medio de cultivo incluye iones metálicos, tales como $\mathrm{Fe}^{2+} \mathrm{y} \mathrm{Cu}^{2+}$, los cuales son inductores de la formación de ERO a través de las reacciones de Fenton y Haber-Weiss, y en el caso del hierro, también puede actuar sobre lípidos generando peroxidación lipídica iniciada por radicales hidroxilos libres ${ }^{(48)}$. La suplementación con fluidos biológicos como es el suero bovino fetal (SBF), puede aumentar los niveles de 
ERO en relación con otros suplementos como la albumina sérica bovina (BSA). La presencia de la enzima amino oxidasa en suero ${ }^{(49)}$, que participa en la oxidación de aminas primarias, genera como producto secundario el peróxido de hidrógeno ${ }^{(50)}$, lo cual podría explicar el efecto de la concentración del suero sobre el porcentaje de apoptosis ${ }^{(51)}$, la criotolerancia y el patrón de expresión génica en embriones bovinos producidos in vitro $^{(52)}$. Sin embargo, este suplemento proteico mejora la tasa de producción y la calidad de embriones bovinos ${ }^{(53)}$. Adicionalmente, para mantener la competencia de desarrollo de los oocitos bovinos durante la maduración in vitro, es necesario regular el contenido de glucosa. Altas concentraciones de glucosa en el medio de maduración incrementan los niveles de ERO y disminuyen el contenido de glutatión (GSH) intracelular en oocitos bovinos, inhibiendo enzimas responsables en la síntesis de GSH y afectando así la capacidad de los oocitos para reducir las $\mathrm{ERO}^{(54,55)}$, las cuales durante el desarrollo embrionario temprano pueden causar peroxidación lipídica de la membrana celular, fragmentación del ADN y afectar la síntesis de proteínas ${ }^{(32,56)}$.

Además, la luz visible también induce la producción de ERO generando oxidación de bases, quiebres en las cadenas del ADN y daño oxidativo en otras biomoléculas ${ }^{(2)}$. Se ha reportado que la motilidad y la hiperactivación espermática se ven afectadas por una producción excesiva de ERO, generada por la exposición a luz visible ${ }^{(57)}$. Además, se ha encontrado una producción excesiva de ERO en embriones in vitro que han sido expuestos transitoriamente a la luz visible, siendo la luz fluorescente blanca fría, que es la luz comúnmente utilizada en los laboratorios, la que más ERO genera en cigotos de ratón y hámster, reflejándose en el índice de apoptosis de blastocisto, pero el uso de filtros ha permitido disminuir los efectos de la luz ${ }^{(58)}$. En adición, estudios en los cuales se evaluaron dos tipos de luz (luz del día y luz del laboratorio) y tiempo de exposición en los medios de cultivo y en embriones porcinos, se encontró que redujo la calidad y los porcentajes de blastocistos partenogenéticos ${ }^{(59)}$. Esto sugiere que los medios de cultivo y los embriones deben ser protegidos de la luz durante los procesos de producción in vitro.

En los procesos de producción in vitro de embriones, el protocolo de preparación y capacitación del semen para la fertilización in vitro requiere el uso de centrifugación. Sin embargo, el tiempo y la fuerza centrífuga son factores que contribuyen a aumentar los niveles de ERO, causando daño oxidativo y afectando la función espermática ${ }^{(5,60)}$. Además, se observó que la centrifugación de espermatozoides sexados y no sexados por largos periodos de tiempo (45 min) a 700 xg causaba pérdida de la integridad de la membrana plasmática y fragmentación del $\mathrm{ADN}^{(61,62)}$. Este resultado sugiere que la membrana plasmática de los espermatozoides sufre un proceso de peroxidación lipídica debido a los altos niveles de ERO, disminuyendo la fluidez de la membrana y la funcionalidad para llevar a cabo la fertilización. Por esta razón, diferentes técnicas de preparación espermática como el "Swim-up" y los gradientes de densidad, han sido usadas para obtener espermatozoides con mayores porcentajes de motilidad e integridad en el ADN, y probablemente mejorar la capacidad fertilizante de los espermatozoides durante los procesos de producción in vitro ${ }^{(63)}$. 
Finalmente, la criopreservación aumenta significativamente la producción de ERO en espermatozoides, afectando la motilidad, viabilidad, capacitación y potenciando la peroxidación lipídica de la membrana espermática, lo cual afecta el potencial de fertilidad $^{(64)}$. En oocitos, las bajas tasas de fertilización de los oocitos criopreservados se relacionaron con los daños por congelamiento, incluido el endurecimiento de la zona pelúcida, debido a la liberación prematura de los gránulos corticales y la desorganización del huso y la pérdida o aglutinación de microtúbulos ${ }^{(65,66)}$. Por lo tanto, el uso de antioxidantes sería un factor importante en la supervivencia y función espermática antes, durante y después de la criopreservación. La Figura 1 muestra los efectos del estrés oxidativo y las fuentes de ERO durante los procesos de producción de embriones in vitro.

Figura 1: Efectos del estrés oxidativo y las fuentes de especies reactivas de oxígeno (ERO) durante la producción de embriones

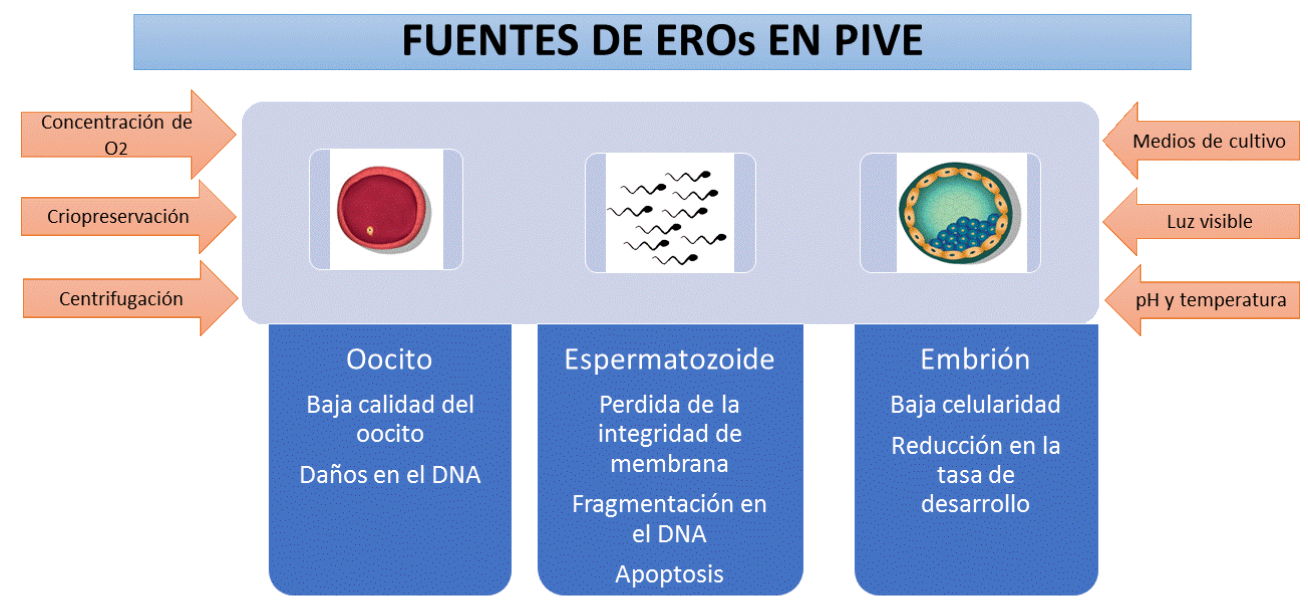

EFECTOS DE EROs EN PIVE

PIVE= Producción in vitro de embriones

\section{Antioxidantes enzimáticos y no enzimáticos}

Un antioxidante con función biológica se define como una sustancia que disminuye o evita la oxidación del sustrato, resultando un agente reductor más potente ${ }^{(67)}$. Las especies reactivas de oxígeno pueden ser inactivadas por un sistema de defensa que consiste en enzimas y moléculas antioxidantes ${ }^{(2)}$. Estos mecanismos antioxidantes pueden ser mediados por proteínas de unión a hierro y cobre, tales como la transferrina, la ferritina y la albúmina ${ }^{(68)}$, por pequeñas moléculas antioxidantes principalmente derivadas de frutas y vegetales, o mecanismos enzimáticos, los cuales incluyen enzimas, tales como 
superóxido dismutasa (SOD), que cataliza la dismutación del anión superóxido en oxígeno y peróxido de hidrógeno; la catalasa (CAT) y glutatión peroxidasa (GPX) que convierten el peróxido de hidrógeno en agua (y oxígeno para la reacción de la CAT); moléculas hidrofílicas como el ascorbato, el urato y el GSH, y lipofílicas como tocoferoles, flavonoides, carotenoides y ubiquinol (Figura 2). También, enzimas involucradas en la reducción de formas oxidadas de pequeñas moléculas antioxidantes, como GSH reductasa y dehidroascorbato reductasa, o moléculas responsables del mantenimiento de grupos tioles en proteínas (tiorredoxina) hacen parte de los mecanismos antioxidantes de la célula ${ }^{(12)}$.

Figura 2: Mecanismos de acción de antioxidantes enzimáticos y no enzimáticos

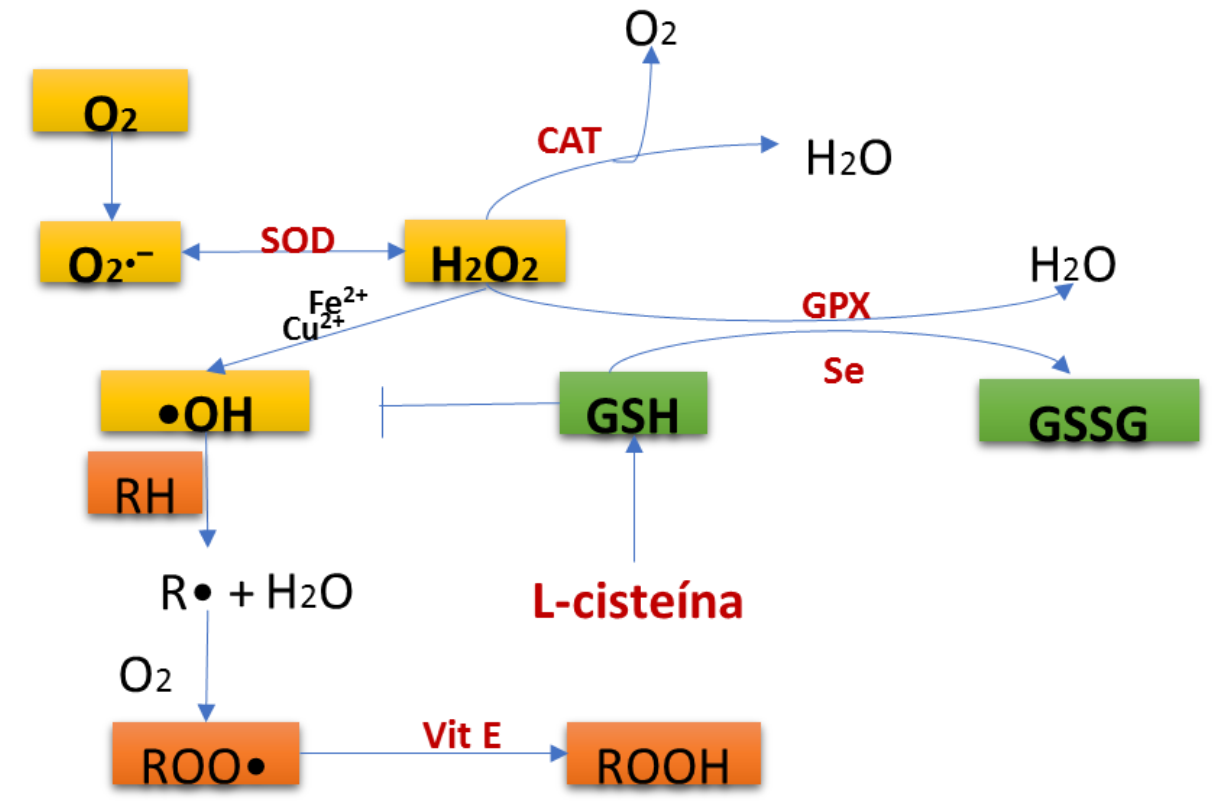

CAT: Catalasa; SOD: Superóxido dismutasa; GPX: Glutatión peroxidasa; Se: Selenio; GSH: Glutatión reducido; GSSG: Glutatión oxidado

R: Lípido; O2: Oxígeno; • OH: radical hidroxilo; $\mathrm{O}^{*^{-}}$:radical superóxido; $\mathrm{H} 2 \mathrm{O} 2$ :peróxido de hidrógeno; $\mathrm{H} 2 \mathrm{O}$ : Agua

El GSH es el mayor componente sulfhidrilo no proteico en las células mamíferas, y es conocido por proteger la célula del daño oxidativo y regula el balance redox intracelular ${ }^{(69)}$; sin embargo, varios estudios han sugerido que el GSH puede jugar un papel importante en muchos procesos biológicos incluyendo la síntesis de ADN y proteínas y proliferación celular durante el desarrollo embrionario ${ }^{(70)}$. En oocitos bovinos, es considerado un importante marcador bioquímico de la viabilidad y la calidad de oocitos mamíferos ${ }^{(71)}$. Adicionalmente, se ha reportado la síntesis de GSH durante la maduración in vitro ${ }^{(72,73)}$, y su asociación con la formación del pronúcleo masculino después de la fecundación ${ }^{(72,74)}$ y el desarrollo embrionario temprano ${ }^{(70)}$. Por lo tanto, los niveles 
intracelulares de GSH son considerados un marcador de calidad del oocito y de su competencia para el desarrollo embrionario después de la fertilización in vitro.

Los antioxidantes más evaluados para suplementar los medios de cultivo son el ácido ascórbico (AA) y el alfa tocoferol (AT). El AT presenta principalmente un efecto benéfico sobre la tasa de blastocistos y su celularidad ${ }^{(75,76)}$, mientras el AA disminuye la producción de ERO en oocitos bovinos, mejorando su potencial para el desarrollo embrionario $^{(9)}$. Para el caso del sistema de producción in vitro de embriones, el antioxidante AT, puede tener ventajas, debido a su hidrofobicidad, que le permite atravesar la bicapa lipídica, intercalarse en ella y disminuir las ERO dentro de la célula. El AA es un antioxidante hidrosoluble, que actúa sinérgicamente con tocoferol en algunas condiciones regenerando tocoferol a partir de radicales tocopheroxyl en un ciclo redox ${ }^{(77)}$. Ha sido reportado que AA disminuyó la producción de ERO en los medios de cultivo y mejoró la competencia de desarrollo embrionario bovino a través de la disminución de ERO intracelular en oocitos madurados con $\mathrm{AA}^{(78)}$. En adición, AA aumentó la tasa de blastocistos y la celularidad ${ }^{(11)}$, aumentó los niveles intracelulares de GSH y disminuyó la producción de EROS en oocitos bovinos ${ }^{(10)}$, mientras durante el CIV, AA disminuyó la producción de ERO y la expresión de genes pro-apoptóticos en embriones porcinos, potenciando el desarrollo embrionario ${ }^{(79)}$ y mejorando la tasa de supervivencia y calidad de embriones vitrificados ${ }^{(80,81)}$.

Además, se observó que el medio de cultivo embrionario suplementado con AT o AA aumentó la capacidad de desarrollo y la celularidad, y redujo la proporción de células apoptóticas en blastocistos porcinos derivados de fecundación in vitro (FIV) o transferencia nuclear de células somáticas (SCNT); sin embargo, este efecto no se observó cuando la suplementación fue combinada ${ }^{(76)}$.

Otros estudios han reportado los efectos benéficos de la melatonina, debido a que tiene una alta capacidad para atrapar radicales libres, reducir la concentración de ERO, aumentar la expresión de enzimas antioxidantes (SOD y glutatión reductasa) ${ }^{(82,83)}$, suprimir la expresión de enzimas pro-oxidantes y mejorar la función mitocondrial ${ }^{(84,85)}$. La melatonina, como muchos antioxidantes, tiene un efecto positivo o deletéreo dependiendo de la concentración que sea usada en el medio de cultivo. Como suplemento en el medio de FIV, a bajas concentraciones mejora la calidad y la motilidad espermática, disminuye los niveles de ERO y la peroxidación lipídica, y actúa como agente antiapoptótico en espermatozoides bovinos $^{(86)}$ y espermatozoides humanos eyaculados $^{(87-89)}$. En contraste, altas concentraciones de melatonina inducen fragmentación y oxidación de DNA espermático, disminuyen el número de espermatozoides viables y generan una disminución en las tasas de blastocistos, sin afectar la calidad embrionaria ${ }^{(90,91)}$. En relación al medio de cultivo embrionario, la melatonina aumenta las tasas de clivaje, blastocisto y eclosión, aumenta la celularidad embrionaria y promueve la activación de enzimas antioxidantes ${ }^{(92,93)}$. 


\section{Antioxidantes fenólicos}

Se han realizado grandes avances en la identificación, purificación y evaluación de moléculas antioxidantes de origen natural ${ }^{(94)}$, como es el caso de los antioxidantes fenólicos, los cuales sirven para inhibir la oxidación de compuestos que tengan importancia biológica o comercial al tener una gran estabilidad, por la presencia de anillos aromáticos en su estructura y la presencia de grupos hidroxilo ${ }^{(94,95)}$. Debido a esto, algunos trabajos señalan su uso potencial como medicamento para la prevención y terapia de enfermedades causadas por los radicales libres tales como la isquemia, aterosclerosis, enfermedades neuronales y cardiovasculares ${ }^{(96,97)}$.

Los antioxidantes fenólicos (ArOH) poseen dos mecanismos de acción: por transferencia de un átomo de hidrógeno (HAT) o por transferencia de un electrón (SET). En el primero, el radical libre $(\mathrm{R} \bullet)$ remueve un átomo de hidrogeno del antioxidante $(\mathrm{ArOH})$, convirtiéndose en un radical $\mathrm{ArO} \bullet$ más estable y más eficiente; debido a que los enlaces de hidrógeno, la conjugación y la resonancia lo convierten en un radical fenoxil no reactivo. En el segundo mecanismo, el antioxidante puede donar un electrón al radical libre formando entre los productos un catión radical del antioxidante $(\mathrm{ArO} \bullet+)$, el cual es estable y no reacciona con sustratos (Figura 3). Ambos mecanismos pueden ocurrir siempre en paralelo, pero con diferentes tasas de reacción ${ }^{(98)}$.

Figura 3: Mecanismos de acción de antioxidantes fenólicos

- Mecanismo por transferencia de un átomo de hidrogeno (HAT)

$$
\mathrm{ArOH}+\mathrm{R} \bullet \rightarrow \mathrm{ArO} \bullet+\mathrm{RH}
$$

Estabilización por resonancia de un radical antioxidante<smiles>O=C1C=CC(C=Cc2cccc(O)c2)=CC1=O</smiles>

- Mecanismo por transferencia de un electrón (SET)

$$
\mathrm{ArOH}+\mathrm{R} \bullet \rightarrow \mathrm{ArO}^{\bullet+}+\mathrm{R}^{-}
$$

Con el objetivo de buscar nuevos antioxidantes y evaluar su actividad en reproducción, el extracto de té verde (cuyos principales componentes son polifenoles), fue evaluado en 
oocitos madurados in vitro, y encontraron una respuesta favorable con respecto a la tasa de blastocistos y a las concentraciones de glutatión reducido dentro del oocito, pero con la limitante de la escasa repetitividad, debido a que el extracto puede variar de composición ${ }^{(99)}$. Otras moléculas de origen biológico con capacidad antioxidante son las antocianinas, la cuales se evaluaron en el medio de maduración de oocitos porcinos ${ }^{(100)}$ y bovinos $^{(101)}$, sobre los diferentes parámetros de calidad del oocito, como son, el nivel de producción de radicales libres, los niveles de glutatión intracelular, la abundancia relativa de RNAm asociados a desarrollo embrionario y su competencia para la producción in vitro de embriones. Además, el efecto benéfico de los compuestos fenólicos presentes en la uva ha comenzado a capturar la atención de los investigadores, como es el caso del resveratrol (3,5,4'-trans-trihidroxiestilbeno) y el pterostilbeno (antioxidante natural análogo de resveratrol), los cuales se han encontrado en forma abundante en plantas y frutos como arándanos, moras, cacahuates, uva y vino tinto ${ }^{(102,103)}$. La actividad del resveratrol y el pterostilbeno se debe a distintas propiedades biológicas, tanto a nivel in vivo como in vitro, tales como su capacidad antioxidante, cardioprotectora, antiinflamatoria, quimiopreventivo en algunos modelos de cáncer y algunos efectos positivos en enfermedades metabólicas ${ }^{(102,104)}$. Estos resultados conllevan a la exploración de efectos biológicos in vitro en otros modelos y sistemas animales como la producción in vitro de embriones.

En relación al pterostilbeno, ha sido reportado que puede reducir los niveles de ERO y el porcentaje de lípidos en embriones, cuando es adicionado el medio de cultivo embrionario $^{(105)}$. Sin embargo, pocos trabajos se han realizado con este tipo de antioxidante en biotecnologías reproductivas, lo que hace necesario realizar más estudios para comprender el mecanismo molecular por el cual el pterostilbeno ejerce su efecto sobre el metabolismo embrionario.

Por otro lado, se han encontrado reportes sobre el uso del resveratrol en la maduración in vitro del oocitos porcinos ${ }^{(106)}$, bovinos $^{(10,107-109)}$ y cabras $^{(110)}$, donde aumenta la concentración de glutatión reducido dentro del oocito, disminuye la producción de ERO y aumenta la tasa de blastocistos. Además, el uso del resveratrol durante el cultivo in vitro de embriones tiene un efecto positivo en el desarrollo embrionario ${ }^{(111)}$ y un aumento en la criotolerancia de blastocistos ${ }^{(112,113)}$, reflejando que la capacidad antioxidante del resveratrol mejora la calidad de los oocitos y su resistencia a los procesos de criopreservación. Sin embargo, cuando la concentración de resveratrol es alta (20 y 40 $\mu \mathrm{M})$ el efecto benéfico desaparece y disminuye el porcentaje de oocitos bovinos capaces de completar el proceso de maduración hasta el estadío de metafase II $^{(114)}$.

El efecto fisiológico del resveratrol parece estar relacionado a su capacidad para potenciar procesos celulares dependientes de Sirtuina 1 (SIRT1), la cual está también relacionada a la proteína quinasa activada por adenosina monofosfato (AMPK), que es un sensor energético que controla el metabolismo celular, incluyendo la fosforilación oxidativa y la oxidación de ácidos grasos ${ }^{(115)}$. La activación de AMPK a través de resveratrol incrementa los niveles de NAD+, el cofactor de SIRT1, el cual disminuye la acetilación de sustratos de SIRT1 y activa PGC-1 $\alpha$ (coactivador $1 \alpha$ del receptor activado gamma del proliferador 
de peroxisoma $)^{(116,117)}$. Sin embargo, se ha encontrado que a pesar de la activación de AMPK para observar los efectos metabólicos del resveratrol, el blanco directo de éste se encuentra corriente arriba de AMPK. Uno de los mecanismos propuestos es que el resveratrol activa AMPK a través de una inhibición competitiva de fosfodiesterasas (PDEs), incrementando los niveles de $\mathrm{AMPc}^{(118)}$. Este segundo mensajero juega un papel importante en la maduración de oocitos mamíferos, el cual es generado después de la unión de la FSH y LH a sus receptores específicos en la membrana plasmática de las células de la granulosa, por la activación de la adenilato ciclasa ${ }^{(119)}$. Los niveles intracelulares del AMPc son regulados por las PDEs, las cuales lo hidrolizan a 5'-AMP. El uso de inhibidores de PDE, generan un retraso del reinicio de la meiosis y una cinética más lenta en la expansión del cúmulo, lo cual prolonga el mantenimiento de las uniones gap entre el oocito y las células del cúmulo ${ }^{(120)}$. Esta prolongación de las uniones gap durante la maduración in vitro en presencia de inhibidores de PDE4 podría permitir el paso de metabolitos, iones, nucleótidos y aminoácidos, que mejoran la maduración citoplasmática del oocito, aproximándose a una sincronización entre la maduración nuclear y citoplasmática, lo cual favorecería la producción y calidad de blastocistos. El Cuadro 1 contiene un resumen de los estudios clave que usaron resveratrol como suplemento antioxidante durante la producción in vitro de embriones.

Cuadro 1:. Resultados de estudios usando resveratrol como suplemento en los medios de cultivo para producción in vitro de embriones

\begin{tabular}{|c|c|c|c|c|c|}
\hline Cultivo & Gametos & Especie & $\begin{array}{l}\text { Concentraciones } \\
\text { de resveratrol }\end{array}$ & Resultados del estudio & Referencia \\
\hline \multirow{7}{*}{ MIV } & \multirow{7}{*}{ oocitos } & Porcino & $\begin{array}{l}0.1,0.5,2.0 \text { y } 10.0 \\
\mu \mathrm{M}\end{array}$ & $\begin{array}{l}\text { Mejoró el desarrollo de embriones } \\
\text { partenogenéticos y fertilizados in vitro, } \\
\text { aumentó el de GSH intracelular y disminuyó los } \\
\text { niveles de ERO }\end{array}$ & (106) \\
\hline & & Porcino & $20 \mu \mathrm{M}$ & $\begin{array}{l}\text { Aumentó la expresión de SIRT1, mejoró las } \\
\text { funciones mitocondriales y la capacidad de } \\
\text { desarrollo de los oocitos }\end{array}$ & (142) \\
\hline & & Porcino & $2 \mu \mathrm{M}$ & $\begin{array}{l}\text { Mejoró la resistencia de los oocitos porcinos a } \\
\text { los daños inducidos por la criopreservación }\end{array}$ & (113) \\
\hline & & Bovino & $0.1,1$ y $10 \mu \mathrm{M}$ & $\begin{array}{l}\text { Indujo la secreción de progesterona, aumentó } \\
\text { el de GSH intracelular y disminuyó los niveles } \\
\text { de ERO, promovió la maduración del oocito y } \\
\text { el subsecuente desarrollo embrionario }\end{array}$ & (107) \\
\hline & & Bovino & $20 \mu \mathrm{M}$ & $\begin{array}{l}\text { Aumentó el contenido de ATP y la expresión de } \\
\text { la proteína SIRT1 en oocitos madurados, } \\
\text { mejoro la fertilización reforzando los } \\
\text { mecanismos responsables del bloqueo de la } \\
\text { poliespermia }\end{array}$ & (143) \\
\hline & & Bovino & $2 \mu \mathrm{M}$ & $\begin{array}{l}\text { Disminuyó los niveles de ERO, aumentó las } \\
\text { tasas de desarrollo embrionario y de } \\
\text { celularidad embrionaria }\end{array}$ & (10) \\
\hline & & Bovino & 20 y $40 \mu \mathrm{M}$ & $\begin{array}{l}\text { Resveratrol regula la expresión del gen } \\
\text { CYP1A1 involucrado en el reinicio de meiosis }\end{array}$ & (114) \\
\hline
\end{tabular}




\begin{tabular}{|c|c|c|c|c|c|}
\hline & & Bovino & $1,10,20$ y $40 \mu \mathrm{M}$ & $\begin{array}{l}\text { Aumentó el desarrollo de embrionario, } \\
\text { aumentó el de GSH intracelular y disminuyó los } \\
\text { niveles de ERO }\end{array}$ & $(108)$ \\
\hline & & Bovino & $\begin{array}{l}0.2 \mu \mathrm{M}, 1 \mu \mathrm{M} \text { y } 20 \\
\mu \mathrm{M}\end{array}$ & $\begin{array}{l}\text { Mejoró la capacidad de desarrollo de los } \\
\text { oocitos, aumentado las tasas de maduración y } \\
\text { las tasas blastocistos }\end{array}$ & $(109)$ \\
\hline & & Bovino & $2 \mu \mathrm{M}$ & $\begin{array}{l}\text { Resveratrol afectó la expresión de la proteína } \\
\text { SIRT1 en oocitos y blastocistos de donantes de } \\
\text { diferentes edades }\end{array}$ & $(144)$ \\
\hline & & Bovino & $2 \mu \mathrm{M}$ & $\begin{array}{l}\text { Disminuyó los niveles de ERO, aumentó los } \\
\text { niveles de GSH y las tasas de clivaje y } \\
\text { blastocisto y disminuyó la expresión de genes } \\
\text { proapoptóticos }\end{array}$ & $(145)$ \\
\hline & & Caprino & $\begin{array}{l}0.1,0.25,0.5,2.0 y \\
5.0 \mu \mathrm{M}\end{array}$ & $\begin{array}{l}\text { Disminuyó los niveles de ERO, aumentó los } \\
\text { niveles de GSH y las tasas de desarrollo } \\
\text { embrionario, y disminuyó la expresión de los } \\
\text { genes proapoptóticos en las células del } \\
\text { cúmulo, oocitos maduros, y blastocistos }\end{array}$ & $(110)$ \\
\hline \multirow[t]{2}{*}{ FIV } & \multirow[t]{2}{*}{ Espermatozoides } & Ratón & $15 \mu \mathrm{g} / \mathrm{ml}$ & $\begin{array}{l}\text { Aumentó de la fertilización de oocitos, } \\
\text { disminuyó la generación de ERO, la actividad } \\
\text { del glutatión peroxidasa y la concentración de } \\
\text { peroxidación lipídica. }\end{array}$ & $(146)$ \\
\hline & & Humano & $0.1,1.0$ y $10.0 \mathrm{mM}$ & $\begin{array}{l}\text { Evitó el daño del ADN inducido por } \\
\text { criopreservación en hombres infértiles }\end{array}$ & $(147)$ \\
\hline \multirow{2}{*}{ CIV } & \multirow{2}{*}{ Embriones } & Porcino & $\begin{array}{l}0.05,0.1,0.5,1.0 y \\
25 \mu \mathrm{M}\end{array}$ & $\begin{array}{l}\text { El resveratrol a } 0.5 \mu \mathrm{M} \text { durante el cultivo } \\
\text { presentó un efecto positivo en el desarrollo } \\
\text { embrionario }\end{array}$ & $(111)$ \\
\hline & & Bovino & $0,0.25,0.5$ y $1 \mu \mathrm{M}$ & $\begin{array}{l}\text { El resveratrol a } 0.5 \mu \mathrm{M} \text { mejoró la calidad de los } \\
\text { embriones y mejoró la criotolerancia } \\
\text { embrionaria }\end{array}$ & $(112)$ \\
\hline
\end{tabular}

\section{Cambios de expresión génica y desórdenes epigenéticos inducidos por ERO}

La competencia de desarrollo de un oocito está definida como la capacidad de un oocito para reiniciar meiosis, ser fertilizado, dividirse y alcanzar el estadio de blastocisto ${ }^{(21)}$. Esta competencia o calidad, es adquirida progresivamente durante la foliculogénesis con el crecimiento del oocito y su maduración a través de una serie de cambios celulares (actividad mitocondrial), moleculares (perfil de expresión génica) y funcionales (actividad de proteína quinasa) ${ }^{(55,122)}$. Durante el crecimiento y maduración del oocito son sintetizadas RNAm y proteínas, los cuales contribuyen al desarrollo temprano antes y después de la activación del genoma embrionario. Este almacenamiento de RNAm se da durante el crecimiento del oocito y se desarrolla un evento de poliadenilación en cada transcripto, como un regulador clave en la expresión de genes y es conocido como un importante paso para el desarrollo del embrión mamífero ${ }^{(123)}$. Sin embargo, las condiciones de maduración in vitro pueden afectar los niveles de poliadenilación en 
mRNAs materno, lo cual puede tener implicaciones en la calidad embrionaria ${ }^{(124)}$. Esto sugiere que deficiencias en la competencia para el desarrollo en la mayoría de los oocitos madurados in vitro, podrían reflejarse en la composición y abundancia de transcriptos de RNAs específicos en el oocito.

Por esta razón, diferentes transcriptos se han evaluado en el oocito con el fin de asociarlos a su calidad o a la competencia para el desarrollo embrionario. Entre los más estudiados están NLRP5 (NLR Family Pyrin Domain Containing 5, conocido como MATER), un gen de efecto maternal específico del oocito requerido para el desarrollo embrionario temprano en bovinos, ratones y humanos ${ }^{(125-127)}$. POU5F1 (POU domain class 5, transcription factor 1) o también conocido como OCT-4, el cual ha sido validado como marcador para reprogramación epigenética y pluripotencia, y es crucial para el desarrollo embrionario normal ${ }^{(128)}$. Se reportó que la expresión de POU5F1 aumentó en embriones porcinos derivados de SCNT tratados con vitamina $\mathrm{C}^{(129)}$.

Adicionalmente, con el objetivo de predecir el éxito de la fertilización y mantener la viabilidad del oocito, la expresión de genes como ácido hialurónico sintetasa 2 (HAS2), ciclooxigenasa 2 (COX2; PTGS2) y gremlin (GREM1) en las células del cumulo han sido correlacionados con competencia del oocito y su subsecuente desarrollo embrionario $^{(111,130)}$.

En el desarrollo de embriones bovinos, la viabilidad celular está determinada por alteraciones en la expresión de genes relacionados al metabolismo como GLUT-1 (glucose transporter-1 transcriptos) ${ }^{(131)}$, factores de crecimiento como IGF-2 (insulin-like growth factor 2) e $I G F-2 R$ (insulin-like growth factor 2 receptor), la diferenciación temprana y funciones trofoblásticas como IF (interferon tau) y Mash2 (mammalian achaetescute homologue $)^{(132,133)}$. Sin embargo, durante los procesos de producción in vitro de embriones no solo se observan cambios en la expresión génica, sino también desórdenes epigenéticos que pueden afectar los patrones de metilación de ADN sobre algunos genes (DNA methyltransferase, DNMTla, DNMT3a y DNMT3b) y por consiguiente afectar los perfiles de expresión génica que codifican para un tejido especifico $^{(134)}$.

Además, se ha evaluado el efecto de los suplementos antioxidantes en los medios de cultivo sobre la regulación de la expresión génica. En el caso del resveratrol durante la maduración in vitro de oocitos porcinos ${ }^{(106,111,135)}$ y caprinos $^{(110)}$, se observó una disminución en los niveles de transcripción de genes relacionados con apoptosis como $B A X, B A K$ y Caspasa-3, mientras que no se observaron cambios en la expresión del gen $B C L-2$. Esto sugiere que el resveratrol suprime la expresión de genes proapoptóticos en oocitos madurados, y ejerce un efecto protector sobre los embriones producidos in vitro. También se observó que la suplementación con AA en el medio reguló positivamente la expresión génica pluripotente en blastocistos porcinos partenogenéticos, y disminuyó la expresión del gen proapoptótico $\mathrm{Bax}^{(79)}$.

Cuando se suplementó el medio de cultivo y los medios de vitrificación- descongelación con AA, se observó que la expresión de los genes asociados a estrés oxidativo GPX1 y 
SOD1 aumentó, mejorando las tasas de supervivencia y disminuyendo los niveles de peróxido a las 24 h pos- descongelación ${ }^{(136)}$. Un reporte anterior en bovinos, encontró que la abundancia relativa de GPXI es mayor en blastocistos de excelente calidad (grado 1) que en blastocistos buenos (grado 2), lo que sugiere que una menor expresión del gen GPX1 se asocia con menor calidad embrionaria ${ }^{(137)}$.

Además, las ERO producidas de manera endógena y exógena durante la PIVE pueden inducir cambios epigenéticos. Condiciones de cultivo que incluyen cambios en el $\mathrm{pH}$, osmolaridad, temperatura, exposición a la luz visible, concentración de oxígeno y centrifugación de las células, pueden afectar el patrón epigenético durante el proceso in vitro afectando la calidad de los gametos y embriones ${ }^{(134)}$. Se ha sugerido que el estrés oxidativo puede producir en los gametos, alteraciones en los patrones de metilación del ADN y modificación de las proteínas histonas, cambios transmisibles de gametos a embriones generando variaciones en el epigenoma que podrían alterar el subsecuente desarrollo embrionario ${ }^{(138-140)}$. Los mecanismos de transmisión al embrión durante la fertilización y el clivaje aún no han sido dilucidados; sin embrago, se sugiere que el daño por estrés oxidativo en el epigenoma de los gametos -los cuales aumentan los aductos en el ADN y las alteraciones en los perfiles de metilación-, son transferidas al embrión, manifestándose en alteraciones fenotípicas observadas en los recién nacidos ${ }^{(141)}$.

Recientemente se ha demostrado que la inducción de estrés oxidativo en espermatozoides utilizando $\mathrm{H}_{2} \mathrm{O}_{2}$ causa daño oxidativo en el epigenoma de los espermatozoides, el cual subsecuentemente reduce las tasas de desarrollo embrionario y altera la diferenciación celular en los blastocistos. Lo cual resulta en una reducción en las tasas de implantación, reducido crecimiento fetal, aumento del tejido adiposo, disminución de la masa magra y reducida tolerancia a la glucosa. Estos hallazgos implican a las ERO como uno de los mecanismos responsables de la transmisión de señales de salud de los padres a los $\operatorname{hijos}^{(141)}$.

\section{Conclusiones}

A pesar de que las técnicas de producción in vitro de embriones se utilizan de manera comercial en la producción animal, es evidente que existen múltiples factores que pueden generar estrés oxidativo y afectar potencialmente la calidad de los oocitos madurados y consecuentemente las tasas de desarrollo embrionario. El ambiente y los procedimientos a los cuales son sometidos los embriones y los gametos, generan un aumento en los niveles de ERO contrario a los niveles fisiológicos requeridos para regular varias funciones celulares, afectando la morfología y funcionalidad de la célula. Estos factores pueden afectar diferentes biomoléculas generando daños en el ADN, peroxidación lipídica, cambios en los niveles de expresión génica y desórdenes epigenéticos. Esto sugiere el uso de moléculas con actividad antioxidante durante la maduración in vitro y la búsqueda de nuevas sustancias de origen natural, que permitan disminuir el estrés 
oxidativo durante los procesos de producción in vitro de embriones, con el fin de mejorar la calidad del oocito y su competencia para el desarrollo embrionario.

\section{Agradecimientos}

Los autores agradecen al Banco de la República, Convenio 201633 Proyecto No. 3.862, por su apoyo a este trabajo.

\section{Literatura citada:}

1. Park JI, Hong JY, Yong HY, Hwang WS, Lim JM, Lee ES. High oxygen tension during in vitro oocyte maturation improves in vitro development of porcine oocytes after fertilization. Anim Reprod Sci 2005;87(1-2):133-141.

2. Du Plessis SS, Makker K, Desai NR, Agarwal A. Impact of oxidative stress on IVF. Expert Rev Obstet Gynecol 2008;3(4):539-554.

3. Martín-Romero FJ, Miguel-Lasobras EM, Domínguez-Arroyo JA, González-Carrera E, Alvarez IS. Contribution of culture media to oxidative stress and its effect on human oocytes. Reprod Biomed Online 2008;17(5):652-661.

4. Will MA, Clark NA, Swain JE. Biological pH buffers in IVF: help or hindrance to success. J Assist Reprod Genet 2011;28(8):711-724.

5. Li Z, Zhou Y, Liu R, Lin H, Liu W, Xiao W, et al. Effects of semen processing on the generation of reactive oxygen species and mitochondrial membrane potential of human spermatozoa. Andrologia 2012;44(3):157-163.

6. Agarwal A, Durairajanayagam D, du Plessis SS. Utility of antioxidants during assisted reproductive techniques: an evidence based review. Reprod Biol Endocrinol 2014;12:112.

7. Blanco MR, Demyda S, Moreno Millán M, Genero E. Developmental competence of in vivo and in vitro matured oocytes: A review. Anim Reprod Sci 2012;9(3):281289.

8. Ali AA, Bilodeau JF, Sirard MA. Antioxidant requirements for bovine oocytes varies during in vitro maturation, fertilization and development. Theriogenology 2003;59(3-4):939-949.

9. Vásquez NA, Torres V, Rojano BA. Efecto del ácido ascórbico durante maduración in vitro de oocitos bovinos en la producción de especies reactivas de oxígeno (ERO) y competencia para el desarrollo embrionario. Inf Tecnol 2014;25(2):141-150. 
10. Sovernigo T, Adona P, Monzani P, Guemra S, Barros F, Lopes F, et al. Effects of supplementation of medium with different antioxidants during in vitro maturation of bovine oocytes on subsequent embryo production. Reprod Domest Anim 2017;52:561-569.

11. Kere M, Siriboon C, Lo N-W, Nguyen NT, Ju J-C. Ascorbic acid improves the developmental competence of porcine oocytes after parthenogenetic activation and somatic cell nuclear transplantation. J Reprod Dev 2013;59(1):78-84.

12. Covarrubias L, Hernández-García D, Schnabel D, Salas-Vidal E, Castro-Obregón S. Function of reactive oxygen species during animal development: Passive or active? Dev Biol 2008;320(1):1-11.

13. Rikans LE, Hornbrook KR. Lipid peroxidation, antioxidant protection and aging. Biochim Biophys Acta. 1997;1362(2-3):116-127.

14. Dalle-Donne I, Rossi R, Giustarini D, Milzani A, Colombo R. Protein carbonyl groups as biomarkers of oxidative stress. Clin Chim Acta 2003;329(1-2):23-38.

15. David SS, O'Shea VL, Kundu S. Base-excision repair of oxidative DNA damage. Nature. 2007;21;447(7147):941-950.

16. Selivanov VA, Votyakova T V, Pivtoraiko VN, Zeak J, Sukhomlin T, Trucco M, et $a l$. Reactive oxygen species production by forward and reverse electron fluxes in the mitochondrial respiratory chain. Beard DA, editor. PLoS Comput Biol 2011 Mar 31;7(3):e1001115.

17. Yakes FM, Van Houten B. Mitochondrial DNA damage is more extensive and persists longer than nuclear DNA damage in human cells following oxidative stress. Proc Natl Acad Sci U S A. 1997;21;94(2):514-519.

18. Finkel T, Holbrook NJ. Oxidants, oxidative stress and the biology of ageing. Nature 2000;9;408(6809):239-247.

19. Chinnery PF, Elliott HR, Hudson G, Samuels DC, Relton CL. Epigenetics, epidemiology and mitochondrial DNA diseases. Int J Epidemiol 2012;41(1):177187.

20. Han Y, Chen JZ. Oxidative stress induces mitochondrial DNA damage and cytotoxicity through independent mechanisms in human cancer cells. Biomed Res Int 2013;2013:1-8.

21. Guo C, Sun L, Chen X, Zhang D. Oxidative stress, mitochondrial damage and neurodegenerative diseases. Neural Regen Res 2013;8(21):2003-2014.

22. Kirkinezos IG, Moraes CT. Reactive oxygen species and mitochondrial diseases. Semin Cell Dev Biol 2001;12(6):449-457.

23. Hernández-García D, Wood CD, Castro-Obregón S, Covarrubias L. Reactive oxygen 
species: A radical role in development? Free Radic Biol Med 2010;49(2):130-143.

24. Shkolnik K, Tadmor A, Ben-Dor S, Nevo N, Galiani D, Dekel N. Reactive oxygen species are indispensable in ovulation. Proc Natl Acad Sci 2011;108(4):1462-1467.

25. Morado SA, Cetica PD, Beconi MT, Dalvit GC. Reactive oxygen species in bovine oocyte maturation in vitro. Reprod Fertil Dev 2009;21(4):608-614.

26. Park EJ, Pezzuto JM, Novelle MG, Wahl D, Diéguez C, Bernier M, et al. [Resveratrol: distribution, properties and perspectives]. J Reprod Dev 2011 Aug 1;1852(3):92-99.

27. Jin S-K, Yang W-X. Factors and pathways involved in capacitation: how are they regulated? Oncotarget 2017;8(2):3600-3627.

28. Gangwar DK, Atreja SK. Signalling events and associated pathways related to the mammalian sperm capacitation. Reprod Domest Anim 2015;50(5):705-711.

29. Henkel RR. Leukocytes and oxidative stress: dilemma for sperm function and male fertility. Asian J Androl. 2011;13(1):43-52.

30. Kothari S, Thompson A, Agarwal A, du Plessis SS. Free radicals: their beneficial and detrimental effects on sperm function. Indian J Exp Biol 2010;48(5):425-435.

31. Bromfield EG, Aitken RJ, Anderson AL, McLaughlin EA, Nixon B. The impact of oxidative stress on chaperone-mediated human sperm-egg interaction. Hum Reprod 2015;30(11):2597-2613.

32. Guerin P, Mouatassim S, Menezo Y. Oxidative stress and protection against reaction oxygen species in the pre-implantation embryo and its surroundings. Reprod Updat 2001;7(2):175-189.

33. Gupta S, Sekhon L, Kim Y, Agarwal A. The role of oxidative stress and antioxidants in assisted reproduction. Curr Womens Health Rev 2010;6(3):227-238.

34. Fischer B, Bavister BD. Oxygen tension in the oviduct and uterus of rhesus monkeys, hamsters and rabbits. Reproduction 1993;99(2):673-679.

35. Oyamada T, Fukui Y. Oxygen tension and medium supplements for in vitro maturation of bovine oocytes cultured individually in a chemically defined medium. J Reprod Dev 2004;50(1):107-117.

36. Corrêa GA, Rumpf R, Mundim TCD, Franco MM, Dode MAN. Oxygen tension during in vitro culture of bovine embryos: Effect in production and expression of genes related to oxidative stress. Anim Reprod Sci 2008;104(2-4):132-142.

37. Balasubramanian S, Son WJ, Kumar BM, Ock SA, Yoo JG, Im GS, et al. Expression pattern of oxygen and stress-responsive gene transcripts at various developmental stages of in vitro and in vivo preimplantation bovine embryos. Theriogenology 
2007;68(2):265-275.

38. Karagenc L, Sertkaya Z, Ciray N, Ulug U, Bahçeci M. Impact of oxygen concentration on embryonic development of mouse zygotes. Reprod Biomed Online 2004;9(4):409-417.

39. Kitagawa Y, Suzuki K, Yoneda A, Watanabe T, Agarwal A, Sharma RK, et al. Effects of oxygen concentration and antioxidants on the in vitro developmental ability, production of reactive oxygen species (ROS), and DNA fragmentation in porcine embryos. Theriogenology 2004;1;62(7):1186-1197.

40. Booth PJ, Holm P, Callesen $\mathrm{H}$. The effect of oxygen tension on porcine embryonic development is dependent on embryo type. Theriogenology. 2005;63(7):2040-2052.

41. Batt P, Gardner D, Cameron A. Oxygen concentration and protein source affect the development of preimplantation goat embryos in vitro. Reprod Fertil Dev 1991;3(5):601.

42. Takahashi M, Keicho K, Takahashi H, Ogawa H, Schultz RM, Okano A. Effect of oxidative stress on development and DNA damage in in-vitro cultured bovine embryos by comet assay. Theriogenology 2000;54(1):137-145.

43. Bontekoe S, Mantikou E, van Wely M, Seshadri S, Repping S, Mastenbroek S. Low oxygen concentrations for embryo culture in assisted reproductive technologies. Cochrane database Syst Rev 2012;(7):CD008950.

44. Takahashi M. Oxidative stress and redox regulation on in vitro development of mammalian embryos. J Reprod Dev 2012;58(1):1-9.

45. Bermejo-Álvarez P, Lonergan P, Rizos D, Gutiérrez-Adan A. Low oxygen tension during IVM improves bovine oocyte competence and enhances anaerobic glycolysis. Reprod Biomed Online 2010;20(3):341-349.

46. Rinaudo P, Giritharan G, Talbi S, Dobson A, Schultz R, Katoh Y, et al. Effects of oxygen tension on gene expression in preimplantation mouse embryos. Fertil Steril 2006;86(4):1265.e1-1265.e36.

47. Combelles CMH, Gupta S, Agarwal A. Could oxidative stress influence the in-vitro maturation of oocytes? Reprod Biomed Online 2009;18(6):864-880.

48. Guerin P. Oxidative stress and protection against reactive oxygen species in the preimplantation embryo and its surroundings. Hum Reprod Update. 2001;7(2):175-189.

49. Conklin DJ, Langford SD, Boor PJ. Contribution of serum and cellular semicarbazide-sensitive amine oxidase to amine metabolism and cardiovascular toxicity. Toxicol Sci 1998;46(2):386-392.

50. Stites TE, Mitchell AE, Rucker RB. Physiological importance of quinoenzymes and the O-quinone family of cofactors. J Nutr 2000;130(4):719-727. 
51. Sudano MJ, Paschoal DM, da Silva Rascado T, Magalhães LCO, Crocomo LF, de Lima-Neto JF, et al. Lipid content and apoptosis of in vitro-produced bovine embryos as determinants of susceptibility to vitrification. Theriogenology 2011;75(7):1211-1220.

52. Rizos D, Gutiérrez-Adán A, Pérez-Garnelo S, De La Fuente J, Boland MP, Lonergan P. Bovine embryo culture in the presence or absence of serum: implications for blastocyst development, cryotolerance, and messenger RNA expression. Biol Reprod 2003;68(1):236-243.

53. Almeida T, Tetzner D, Saraiva NZ, Perecin F, Cristina S, Niciura M, et al. The effects of ovalbumin as a protein source during the in vitro production of bovine embryos. Rev Bras Zootec 2011;40(10):2135-2141.

54. Hashimoto S, Minami N, Yamada M, Imai H. Excessive concentration of glucose during in vitro maturation impairs the developmental competence of bovine oocytes after in vitro fertilization: Relevance to intracellular reactive oxygen species and glutathione contents. Mol Reprod Dev 2000;56(4):520-526.

55. Krisher RL, Brad AM, Herrick JR, Sparman ML, Swain JE. A comparative analysis of metabolism and viability in porcine oocytes during in vitro maturation. Anim Reprod Sci 2007;98(1-2):72-96.

56. Hashimoto S, Minami N, Takakura R, Yamada M. Low oxygen tension during in vitro maturation is beneficial for supporting the subsequent development of bovine cumulus \pm oocyte complexes. Mol Reprod Dev 2000;57:353-60.

57. Shahar S, Wiser A, Ickowicz D, Lubart R, Shulman A, Breitbart H. Light-mediated activation reveals a key role for protein kinase A and sarcoma protein kinase in the development of sperm hyper-activated motility. Hum Reprod 2011;26(9):22742282.

58. Takenaka M, Horiuchi T, Yanagimachi R. Effects of light on development of mammalian zygotes. Proc Natl Acad Sci U S A. 2007;104(36):14289-14293.

59. Li R, Liu Y, Pedersen HS, Callesen H. Effect of ambient light exposure of media and embryos on development and quality of porcine parthenogenetically activated embryos. Zygote 2015;23(03):378-383.

60. Lampiao F, Strijdom H, Du Plessis S. Effects of sperm processing techniques involving centrifugation on nitric oxide, reactive oxygen species generation and sperm function. Open Androl J 2010;2:1-5.

61. Urrego R, Ríos A, Ángel MO, Camargo O. Efecto de la centrifugación sobre la membrana plasmática y el ADN de espermatozoides bovinos. Rev Colomb Ciencias Pecu 2008;21(1):19-26.

62. Ángel D, Pérez N, Pareja A, Camargo O, Urrego R. Efecto de la preparación 
espermática previo a la fertilización sobre la membrana plasmática y el adn de semen bovino sexado in vitro. Rev CES 2009;4(2):29-37.

63. Jayaraman V, Upadhya D, Narayan PK, Adiga SK. Sperm processing by swim-up and density gradient is effective in elimination of sperm with DNA damage. J Assist Reprod Genet 2012;29(6):557-563.

64. Bilodeau JF, Chatterjee S, Sirard MA, Gagnon C. Levels of antioxidant defenses are decreased in bovine spermatozoa after a cycle of freezing and thawing. Mol Reprod Dev 2000;55(3):282-288.

65. Hwang IS, Hochi S. Recent progress in cryopreservation of bovine oocytes. Biomed Res Int 2014;2014:1-11.

66. Carroll J, Depypere H, Matthews CD. Freeze-thaw-induced changes of the zona pellucida explains decreased rates of fertilization in frozen-thawed mouse oocytes. $\mathrm{J}$ Reprod Fertil 1990;90(2):547-53.

67. Tirzitis G, Bartosz G. Determination of antiradical and antioxidant activity: Basic principles and new insights. Acta Biochim Pol 2010;57(2):139-142.

68. Kirschvink N, Moffarts B De, Lekeux P. The oxidant/antioxidant equilibrium in horses. Vet J 2008;177(2):178-191.

69. Battin EE, Brumaghim JL. Antioxidant activity of sulfur and selenium: A review of reactive oxygen species scavenging, glutathione peroxidase, and metal-binding antioxidant mechanisms. Cell Biochem Biophys 2009;55(1):1-23.

70. De Matos DG, Gasparrini B, Pasqualini SR, Thompson JG. Effect of glutathione synthesis stimulation during in vitro maturation of ovine oocytes on embryo development and intracellular peroxide content. Theriogenology. 2002;57(5):14431451.

71. Zuelke KA, Jeffay SC, Zucker RM, Perreault SD. Glutathione (GSH) concentrations vary with the cell cycle in maturing hamster oocytes, zygotes, and pre-implantation stage embryos. Mol Reprod Dev 2003;64(1):106-112.

72. Miyamura M, Yoshida M, Hamano S, Kuwayama M. Glutathione concentration during maturation and fertilization in bovine oocytes. Theriogenology 1995;43(1):282.

73. De Matos DG, Furnus CC, Moses DF, Martinez AG, Matkovic M. Stimulation of glutathione synthesis of in vitro matured bovine oocytes and its effect on embryo development and freezability. Mol Reprod Dev 1996;45(4):451-457.

74. de Matos DG, Furnus CC, Moses DF. Glutathione synthesis during in vitro maturation of bovine oocytes: role of cumulus cells. Biol Reprod. 1997;57(6):14201425. 
75. Olson SE, Seidel GE. Culture of in vitro-produced bovine embryos with vitamin $\mathrm{E}$ improves development in vitro and after transfer to recipients. Biol Reprod 2000;62(2):248-252.

76. Jeong YW, Park SW, Hossein MS, Kim S, Kim JH, Lee SH, et al. Antiapoptotic and embryotrophic effects of alpha-tocopherol and L-ascorbic acid on porcine embryos derived from in vitro fertilization and somatic cell nuclear transfer. Theriogenology 2006;66(9):2104-2112.

77. Halliwell B, Gutteridge JM. The antioxidants of human extracellular fluids. Arch Biochem Biophys 1990;280(1):1-8.

78. Vásquez NA, Torres V, Rojano BA. Efecto del ácido ascórbico durante maduración in vitro de oocitos bovinos en la producción de especies reactivas de oxígeno (ERO) y competencia para el desarrollo embrionario. Inf Tecnol 2014;25(2):141-50.

79. Hu J, Cheng D, Gao X, Bao J, Ma X, Wang H. Vitamin C enhances the in vitro development of porcine pre-implantation embryos by reducing oxidative stress. Reprod Domest Anim 2012;47(6):873-879.

80. Castillo-Martín M, Yeste M, Soler A, Morató R, Bonet S. Addition of 1-ascorbic acid to culture and vitrification media of IVF porcine blastocysts improves survival and reduces HSPA1A levels of vitrified embryos. Reprod Fertil Dev 2015;27(7):11151123.

81. Castillo-Martín M, Bonet S, Morató R, Yeste M. Comparative effects of adding $\beta$ mercaptoethanol or L-ascorbic acid to culture or vitrification-warming media on IVF porcine embryos. Reprod Fertil Dev 2014;26(6):875-882.

82. Kaur H, Bhatla SC. Melatonin and nitric oxide modulate glutathione content and glutathione reductase activity in sunflower seedling cotyledons accompanying salt stress. Nitric Oxide 2016;59:42-53.

83. Li B, He X, Zhuang M, Niu B, Wu C, Mu H, et al. Melatonin ameliorates busulfaninduced spermatogonial stem cell oxidative apoptosis in mouse testes. Antioxid Redox Signal 2018;28(5):385-400.

84. Zhang HM, Zhang Y. Melatonin: A well-documented antioxidant with conditional pro-oxidant actions. J Pineal Res 2014;57(2):131-146.

85. Loren P, Sánchez R, Arias ME, Felmer R, Risopatrón J, Cheuquemán C. Melatonin scavenger properties against oxidative and nitrosative stress: Impact on gamete handling and in vitro embryo production in humans and other mammals. Int $\mathrm{J}$ Mol Sci 2017;18(6):1-17.

86. Pang Y-W, Sun Y-Q, Jiang X-L, Huang Z-Q, Zhao S-J, Du W-H, et al. Protective effects of melatonin on bovine sperm characteristics and subsequent in vitro embryo development. Mol Reprod Dev 2016;83(11):993-1002. 
87. Espino J, Ortiz Á, Bejarano I, Lozano GM, Monllor F, García JF, et al. Melatonin protects human spermatozoa from apoptosis via melatonin receptor- and extracellular signal-regulated kinase-mediated pathways. Fertil Steril 2011;95(7):2290-2296.

88. Espino J, Bejarano I, Ortiz Á, Lozano GM, García JF, Pariente JA, et al. Melatonin as a potential tool against oxidative damage and apoptosis in ejaculated human spermatozoa. Fertil Steril 2010;94(5):1915-1917.

89. Karimfar M, Niazvand F, Haghani K, Ghafourian S, Shirazi R, Bakhtiyari S. The protective effects of melatonin against cryopreservation-induced oxidative stress in human sperm. Int J Immunopathol Pharmacol 2015;28(1):69-76.

90. Cheuquemán C, Arias ME, Risopatrón J, Felmer R, Álvarez J, Mogas T, et al. Supplementation of IVF medium with melatonin: Effect on sperm functionality and in vitro produced bovine embryos. Andrologia 2015;47(6):604-615.

91. Succu S, Pasciu V, Manca ME, Chelucci S, Torres-Rovira L, Leoni GG, et al. Dosedependent effect of melatonin on postwarming development of vitrified ovine embryos. Theriogenology 2014;81(8):1058-1066.

92. Mehaisen GMK, Saeed AM, Gad A, Abass AO, Arafa M, El-Sayed A. Antioxidant Capacity of melatonin on preimplantation development of fresh and vitrified rabbit embryos: Morphological and molecular aspects. Fraidenraich D, editor. PLoS One. 2015;10(10):e0139814.

93. Dehghani-Mohammadabadi M, Salehi M, Farifteh F, Nematollahi S, Arefian E, Hajjarizadeh A, et al. Melatonin modulates the expression of BCL-xl and improve the development of vitrified embryos obtained by IVF in mice. J Assist Reprod Genet 2014;31(4):453-461.

94. Dimitrios B. Sources of natural phenolic antioxidants. Trends Food Sci Technol 2006;17(9):505-512.

95. Wright JS, Johnson ER, DiLabio GA. Predicting the activity of phenolic antioxidants: theoretical method, analysis of substituent effects, and application to major families of antioxidants. J Am Chem Soc 2001;123(6):1173-1183.

96. Negi G, Kumar A, Kaundal RK, Gulati A, Sharma SS. Functional and biochemical evidence indicating beneficial effect of Melatonin and Nicotinamide alone and in combination in experimental diabetic neuropathy. Neuropharmacology 2010;58(3):585-592.

97. Kumar A, Sharma SS. NF-kB inhibitory action of resveratrol: A probable mechanism of neuroprotection in experimental diabetic neuropathy. Biochem Biophys Res Commun 2010;394(2):360-365.

98. Rojano B, Gaviria CA, Gil MA, Saez JA, Schinella G, Tournier H. Actividad 
antioxidante del isoespintanol en diferentes medios. Vitae, Rev La Fac Quim Farm 2008;15(63):173-181.

99. Wang ZG, Yu SD, Xu ZR. Effect of supplementation of green tea polyphenols on the developmental competence of bovine oocytes in vitro. Braz J Med Biol Res 2007;40(8):1079-1085.

100. You J, Kim J, Lim J, Lee E. Anthocyanin stimulates in vitro development of cloned pig embryos by increasing the intracellular glutathione level and inhibiting reactive oxygen species. Theriogenology 2010;74(5):777-785.

101. Sakatani M, Suda I, Oki T, Kobayashi S, Kobayashi S, Takahashi M. Effects of purple sweet potato anthocyanins on development and intracellular redox status of bovine preimplantation embryos exposed to heat shock. J Reprod Dev 2007;53(3):605-614.

102. Gambini J, Inglés M, Olaso G, Lopez-Grueso R, Bonet-Costa V, Gimeno-Mallench L, et al. Properties of resveratrol: In vitro and in vivo studies about metabolism, bioavailability, and biological effects in animal models and humans. Oxid Med Cell Longev 2015;2015:837042.

103. Rimando AM, Kalt W, Magee JB, Dewey J, Ballington JR. Resveratrol, pterostilbene, and piceatannol in Vaccinium berries. J Agric Food Chem 2004;52(15):4713-4719.

104. McCormack D, McFadden D. A review of pterostilbene antioxidant activity and disease modification. Oxid Med Cell Longev 2013;2013:575482.

105. Sosa F, Fernando de la Torre J, Alvarez H, Perez S, Kjelland ME, Romo S. 84 Pterostilbene can reduce the percentage of lipids and reactive oxygen species in in vitro-produced bovine embryos [resumen]. Reprod Fertil Dev 2017;29(1):149.

106. Kwak S-S, Cheong S-AA, Jeon Y, Lee E, Choi K-CC, Jeung E-BB, et al. The effects of resveratrol on porcine oocyte in vitro maturation and subsequent embryonic development after parthenogenetic activation and in vitro fertilization. Theriogenology 2012;78(1):86-101.

107. Wang F, Tian X, Zhang L, He C, Ji P, Li Y, et al. Beneficial effect of resveratrol on bovine oocyte maturation and subsequent embryonic development after in vitro fertilization. Fertil Steril 2014;101(2):577-586.

108. Torres V, Urrego R, Echeverry JJ, Lopez A. 181 Resveratrol during in vitro maturation improves the quality of bovine oocyte and enhances embryonic. Reprod Fertil Dev 2016;29:199-209.

109. Kordowitzki P, Bernal SM, Herrmann D, Aldag P, Niemann H. Resveratrol supplementation during in vitro maturation and fertilisation enhances developmental competence of bovine oocytes [resumen]. Reprod Fertil Dev 2016;28(2):230. 
110. Mukherjee A, Malik H, Saha AP, Dubey A, Singhal DK, Boateng S, et al. Resveratrol treatment during goat oocytes maturation enhances developmental competence of parthenogenetic and hand-made cloned blastocysts by modulating intracellular glutathione level and embryonic gene expression. J Assist Reprod Genet 2014;31(2):229-239.

111. Lee K, Wang C, Chaille JM, Machaty Z. Effect of resveratrol on the development of porcine embryos produced in vitro. J Reprod Dev 2010;56(3):330-335.

112. Salzano A, Albero G, Zullo G, Neglia G, Abdel-Wahab A, Bifulco G, et al. Effect of resveratrol supplementation during culture on the quality and cryotolerance of bovine in vitro produced embryos. Anim Reprod Sci 2014;151(3-4):91-96.

113. Giaretta E, Spinaci M, Bucci D, Tamanini C, Galeati G. Effects of resveratrol on vitrified porcine oocytes. Oxid Med Cell Longev 2013;2013.

114. Pocar P, Augustin R, Fischer B. Constitutive expression of CYP1A1 in bovine cumulus oocyte-complexes in vitro: Mechanisms and biological implications. Endocrinology 2004;145(4):1594-1601.

115. Price NL, Gomes AP, Ling AJY, Duarte FV, Martin-Montalvo A, North BJ, et al. SIRT1 is required for AMPK activation and the beneficial effects of resveratrol on mitochondrial function. Cell Metab 2012;15(5):675-690.

116. Kulkarni SS, Cantó C. The molecular targets of resveratrol. Biochim Biophys Acta 2015;1852:1114-1123.

117. Chang HC, Guarente L. SIRT1 and other sirtuins in metabolism. Trends Endocrinol Metab 2014;25(3):138-145.

118. Park S, Ahmad F, Philp A, Baar K, Williams T, Ke H, et al. Resveratrol ameliorates aging-related metabolic phenotypes by inhibiting cAMP phosphodiesterases. Cell 2012;148(3):421-433.

119. Mayes MA, Sirard M-A. Effect of type 3 and type 4 phosphodiesterase inhibitors on the maintenance of bovine oocytes in meiotic arrest. Biol Reprod 2002;66(1):180184.

120. Thomas RE, Thompson JG, Armstrong DT, Gilchrist RB. Effect of specific phosphodiesterase isoenzyme inhibitors during in vitro maturation of bovine oocytes on meiotic and developmental capacity. Biol Reprod 2004;71(4):1142-1149.

121. Sirard MA, Richard F, Blondin P, Robert C. Contribution of the oocyte to embryo quality. Theriogenology 2006;65(1):126-136.

122. Torner H, Ghanem N, Ambros C, Hölker M, Tomek W, Phatsara C, et al. Molecular and subcellular characterisation of oocytes screened for their developmental competence based on glucose-6-phosphate dehydrogenase activity. Reproduction 
2008;135(2):197-212.

123. Lequarre AS, Traverso JM, Marchandise J, Donnay I. Poly(A) RNA is reduced by half during bovine oocyte maturation but increases when meiotic arrest is maintained with CDK inhibitors. Biol Reprod 2004;71(2):425-431.

124. Bilodeau-Goeseels S, Panich P. Effects of oocyte quality on development and transcriptional activity in early bovine embryos. Anim Reprod Sci 2002;71(34):143-155.

125. Tong Z-B, Bondy CA, Zhou J, Nelson LM. A human homologue of mouse mater, a maternal effect gene essential for early embryonic development. Hum Reprod 2002;17(4):903-911.

126. Pennetier S, Perreau C, Uzbekova S, Thélie A, Delaleu B, Mermillod P, et al. MATER protein expression and intracellular localization throughout folliculogenesis and preimplantation embryo development in the bovine. BMC Dev Biol 2006;6:26.

127. Urrego R, Herrera-Puerta E, Chavarria NA, Camargo O, Wrenzycki C, RodriguezOsorio N. Follicular progesterone concentrations and messenger RNA expression of MATER and OCT-4 in immature bovine oocytes as predictors of developmental competence. Theriogenology 2015;83(7):1179-1187.

128. Habermann FA, Wuensch A, Sinowatz F, Wolf E. Reporter genes for embryogenesis research in livestock species. Theriogenology 2007;68(Supl. 1):116-124.

129. Huang Y, Tang X, Xie W, Zhou Y, Li D, Zhou Y, et al. Vitamin C enhances in vitro and in vivo development of porcine somatic cell nuclear transfer embryos. Biochem Biophys Res Commun 2011;411(2):397-401.

130. McKenzie LJ, Pangas SA, Carson SA, Kovanci E, Cisneros P, Buster JE, et al. Human cumulus granulosa cell gene expression: A predictor of fertilization and embryo selection in women undergoing IVF. Hum Reprod 2004;19(12):2869-2874.

131. Lopes AS, Wrenzycki C, Ramsing NB, Herrmann D, Niemann H, Løvendahl P, et al. Respiration rates correlate with mRNA expression of G6PD and GLUT1 genes in individual bovine in vitro-produced blastocysts. Theriogenology 2007;68(2):223236.

132. Wrenzycki C, Wells D, Herrmann D, Miller A, Oliver J, Tervit R, et al. Nuclear transfer protocol affects messenger RNA expression patterns in cloned bovine blastocysts. Biol Reprod 2001;65(1):309-317.

133. Rizos D, Lonergan P, Boland MP, Arroyo-García R, Pintado B, de la Fuente J, et al. Analysis of differential messenger RNA expression between bovine blastocysts produced in different culture systems: Implications for blastocyst quality. Biol Reprod 2002;66(3):589-595. 
134. Urrego R, Rodriguez-Osorio N, Niemann H. Epigenetic disorders and altered gene expression after use of assisted reproductive technologies in domestic cattle. Epigenetics 2014;9(6):803-815.

135. Lee S, Park EJ, Moon JH, Kim SJ, Song K, Lee BC. Sequential treatment with resveratrol-trolox improves development of porcine embryos derived from parthenogenetic activation and somatic cell nuclear transfer. Theriogenology 2016;84(1):145-154.

136. Castillo-Martín M, Bonet S, Morató R, Yeste M. Supplementing culture and vitrification-warming media with 1-ascorbic acid enhances survival rates and redox status of IVP porcine blastocysts via induction of GPX1 and SOD1 expression. Cryobiology 2014;68(3):451-458.

137. Cebrian-Serrano A, Salvador I, García-Roselló E, Pericuesta E, Pérez-Cerezales S, Gutierrez-Adán A, et al. Effect of the bovine oviductal fluid on in vitro fertilization, development and gene expression of in vitro-produced bovine blastocysts. Reprod Domest Anim 2013;48(2):331-338.

138. Brykczynska U, Hisano M, Erkek S, Ramos L, Oakeley EJ, Roloff TC, et al. Repressive and active histone methylation mark distinct promoters in human and mouse spermatozoa. Nat Struct Mol Biol 2010;17(6):679-687.

139. Heinzmann J, Hansmann T, Herrmann D, Wrenzycki C, Zechner U, Haaf T, et al. Epigenetic profile of developmentally important genes in bovine oocytes. Mol Reprod Dev 2011;78(3):188-201.

140. De Castro LS, De Assis PM, Siqueira AFP, Hamilton TRS, Mendes CM, Losano JDA, et al. Sperm oxidative stress is detrimental to embryo development: A dosedependent study model and a new and more sensitive oxidative status evaluation. Oxid Med Cell Longev 2016;2016:1-12.

141. Lane M, McPherson NO, Fullston T, Spillane M, Sandeman L, Kang WX, et al. Oxidative stress in mouse sperm impairs embryo development, fetal growth and alters adiposity and glucose regulation in female offspring. PLoS One. 2014;9(7):19.

142. Sato D, Itami N, Tasaki H, Takeo S, Kuwayama T, Iwata H, et al. Relationship between mitochondrial DNA copy number and SIRT1 expression in porcine oocytes. Ling F, editor. PLoS One 2014;9(4):e94488.

143. Takeo S, Sato D, Kimura K, Monji Y, Kuwayama T, Kawahara-Miki R, et al. Resveratrol improves the mitochondrial function and fertilization outcome of bovine oocytes. J Reprod Dev 2014;60(2):92-99.

144. Kordowitzki P, Klein S, Hadeler K-G, Aldag P, Nowak-Imialek M, Lucas-Hahn A, et al. SIRT1-A possible marker for reproductive aging of in vivo-derived bovine 
oocytes? [resumen]. Reprod Fertil Dev 2017;29(1):109.

145. Lee S, Park EJ, Moon JH, Kim SJ, Song K, Lee BC. Sequential treatment with resveratrol-trolox improves development of porcine embryos derived from parthenogenetic activation and somatic cell nuclear transfer. Theriogenology 2015;84(1):145-154.

146. Mojica-Villegas MA, Izquierdo-Vega JA, Chamorro-Cevallos G, Sánchez-Gutiérrez M. Protective effect of resveratrol on biomarkers of oxidative stress induced by iron/ascorbate in mouse spermatozoa. Nutrients 2014;6(2):489-503.

147. Branco CS, Garcez ME, Pasqualotto FF, Erdtman B, Salvador M. Resveratrol and ascorbic acid prevent DNA damage induced by cryopreservation in human semen. Cryobiology 2010;60(2):235-237. 